\title{
Sanchos contra Quijotes. Un paradigma ibérico contra el Estado Novo y el franquismo
}

\author{
ANTONIO RIVERO MACHINA
}

\begin{abstract}
Sanchos against Quijotes. An Iberian Paradigm Against the Estado Novo and Francoism. The current article analyses the presence of Don Quixote's myth in the poetry related to the opposition against the regimes of Francisco Franco and António de Oliveira Salazar in Spain and Portugal. These poems are written by several Portuguese and Spanish poets between the years of the Spanish Civil War and the sixties. In this corpus of texts we can observe a particular treatment of Sancho Panza's and Quixote's figures. In this sense, we have worked with the poetic texts of José Gomes Ferreira, Mário Dionísio, Miguel Torga, Gabriel Celaya and José Saramago. All these texts adopt a negative view - with the exception of Miguel Torga - of the character of Don Quijote de la Mancha, which is identified with hypocrisy and selfishness of the privileged class. On the contrary, in all these poets, and particularly the writers of Communist affiliation, the figure of Sancho Panza appear dignified as a symbol of the Iberian proletariat. In this common scheme, however, there can be seen different nuances between the examined poems, showing a kinder treatment of the figure of Don Quixote in the writings of Saramago or Torga, as against Gomes Ferreira and Dionísio. Also, an interesting development is seen between the poems written during the Spanish Civil War-Torga, Gomes Ferreira and Dionísio- and written twenty and thirty years later - Celaya and Saramago, when the Iberian dictatorships of the twentieth century enter their final phase. In conclusion, it is possible to determine a common paradigm in the treatment of the quixotic myth in the Spanish-Portuguese poetry during the middle decades of the twentieth century.
\end{abstract}

Keywords: Don Quixote; Iberism; Anti-francoism poetry; Anti-salazarism

Desde su misma publicación en 1605, la potencia del simbolismo quijotesco ha atraído siempre a quien se haya querido acercar, desde muy distintos enfoques, a la cultura hispánica. Mucho se ha dicho y mucho se continuará diciendo al respecto. Generalmente, parece obvio, es ese Caballero de la Triste Figura, cuyo nombre civil era Alonso Quijano, el símbolo sobre el que se suele verter muy distintos valores culturales o contraculturales: la lucidez de la locura, el idealismo desinteresado, el afán de trascendencia del alma sobre nuestra condición material, etc. Casi todos ellos valores positivos, fueran pasados por 
Sanchos contra Quijotes. Un paradigma ibérico contra el Estado Novo y el franquismo

el matiz romántico decimonónico, el nacionalismo del entresiglo o el afán contestatario de las vanguardias. Lecturas que en ocasiones han ido cada vez más lejos de la nada inocente caricatura de partida propuesta por Cervantes en aquella magistral colección de bromas y veras. En las siguientes líneas, sin embargo, nos centraremos, de entre todas ellas, en una lectura muy concreta, surgida a la sazón en un contexto histórico también muy concreto. Una lectura que, por cierto, subvierte por momentos la jerarquía dada entre el Caballero que da nombre a la novela y su escudero, el materialista, epicúreo y olvidado Sancho Panza. Una subversión que dota, en algunas ocasiones, de valores absolutamente negativos al Caballero de la Triste Figura. Estaríamos, en suma, ante una verdadera rebelión de Sancho contra Quijote.

Nos fijamos pues en un corpus poético muy reconocible: la poesía portuguesa escrita durante la dictadura del Estado Novo (Abreu 2006). Una poesía que, en lo que a este trabajo importa, mirará al país situado al otro lado de la Raya mucho más de lo que se suele afirmar. Así sucedió particularmente durante el estallido de la infausta guerra de Espanha, en la que la alianza diplomática y militar -más o menos indisimulada- entre Oliveira Salazar y el general Franco avivó la lógica comunión entre la oposición antisalazarista y el bando republicano español. La guerra española se convirtió, de facto, en un acontecimiento sentido como propio entre muchos escritores portugueses, tanto entre los cuadros del salazarismo como, particularmente, entre los militantes de la oposición en la clandestinidad. Con distintos grados de implicación política, en esta última senda encontraremos, a lo largo de la dictadura, a poetas de la talla de José Gomes Ferreira, Mário Dionísio, Miguel Torga o José Saramago, entre otros menos conocidos. Todos ellos fijaron su mirada en la pareja cervantina de Don Quijote y Sancho Panza como símbolo no ya de ningún pasado legendario, sino del triste presente de opresión y tiranía en que tanto España como Portugal, según denunciaban tales escritores, se encontrarían inmersos.

\section{Desde la militancia neorrealista: José Gomes Ferreira y Mário Dionísio}

Han sido varios críticos, además de los propios protagonistas, los que han destacado la importancia de la Guerra Civil española en la conformación interna de una poética neorrealista portuguesa, dentro y fuera de la colección del Novo Cancioneiro y su ámbito de influencia (Marques Fernandes 2007). El mejor ejemplo lo encarna uno de los poetas centrales del neorrealismo portugués, José Gomes Ferreira, quien en 1948 publicaba el primer tomo de su Poesia (Coímbra, Minerva). Entre los libros que componían dicho volumen encontramos A Morte de 
D. Quixote, una colección integrada por ocho poemas escritos entre 1935 y 1936. A Morte de D. Quixote se redacta pues en los momentos previos a la inminente contienda, en un contexto de oposición al gobierno derechista de la CEDA seguido del posterior triunfo del Frente Popular y sus programas de reforma agraria. El tratamiento de la figura de Don Quijote en este repertorio de ocho poemas será, desde una lectura política inequívoca, absolutamente negativo. En su brevísimo poemario, Gomes Ferreira identifica el idealismo vano del personaje cervantino con las falacias de la clase acomodada, apostando a cambio por la lucha materialista de las masas pobres personificadas por Sancho Panza. Una visión en negativo del mito quijotesco que estaba indudablemente ligada a la euforia frentepopulista de febrero de 1936 y sus demandas en materia de políticas agrarias. Su tercer poema es el más célebre de todos ellos.

Pobres, gritai comigo:

Abaixo o D. Quixote

com cabeça de nuvens

e espada de papelão!

(E viva o Chicote

no silêncio da nossa Mão!)

Pobres, gritai comigo:

Abaixo o D. Quixote

que só nos emperra

de neblina!

(E viva o Archote

que incendeia a terra,

mas ilumina!)

Pobres, gritai comigo:

Abaixo o cavaleiro

de lança de soluços

e bola de sabão

no elmo de barbeiro!

(E vivam os nossos Pulsos

que, num repelão,

hão-de rasgar o nevoeiro!)

(José Gomes Ferreira, A morte de don Quixote, 1936) ${ }^{1}$

1 Tomado de Gomes Ferreira 1990: 74-75. 
Sanchos contra Quijotes. Un paradigma ibérico contra el Estado Novo y el franquismo

La lectura es clara: se llama a derrocar a un don Quijote que "só nos emperra de neblina" para que los pobres -entendidos así como el "nosotros" del alegatopuedan recuperar lo que es suyo. El poema -a la sazón musicado en 1973 por el cantautor Manuel Freire con gran éxito- rebosa, en este sentido, un grito optimista y combativo. Un optimismo que en Gomes Ferreira irá decayendo conforme avance la guerra española y la victoria republicana - con su posible eco en Portugal- quede cada vez más alejada de lo posible. En este sentido, será otro de los libros que componen la Poesia (Coímbra, Minerva, 1948) de Gomes Ferreira el que tenga en la guerra de Espanha su eje central. No en vano, el poeta portuense reunía en Heroicas cuarenta poemas escritos entre 1936 y 1939 que, obviamente, no habían podido ver la luz pública durante el conflicto. La presencia del enfrentamiento fratricida desatado en España, entendido aquí como la lucha por la libertad del pueblo frente al yugo fascista, es absoluta. Su identificación con el bando republicano, total. No obstante, frente al optimismo combativo visto en A Morte de D. Quixote, en Heroicas el derrotismo va avanzando - como en la propia guerra- hacia sus últimas páginas. De esta manera, el desenlace de la guerra y el desenlace del poemario coinciden en un clamor de pesimismo y rabia. Así, con especial dolor, en el último de los poemas dedicado, a la sazón, a la rendición de Madrid. Este largo y enardecido texto de Gomes Ferreira testimonia como pocos la captación ejercida por el grupo neorrealista de la Guerra Civil española como tópica que le era propia y que les definía en oposición a la poesía de evasión de la que se acusaba a vates como José Régio, fundamentalmente, y otros tantos autores vinculados a Presença.

Ódio às lágrimas mal choradas diante dos poentes, à alegria das crianças mortas que teimam em rir nos olhos dos velhos, às noites de insónia por causa duma mulher, às flores que iluminam os mortos de alma, ao álcool da arte-pura-para-esquecer

(José Gomes Ferreira, Heroicas, 1939)²

Aquel lagrimeo del que se acusaba a los presencistas como Régio bien podría llevarnos a pensar en las “neblinas” perseguidas por don Quijote. En cualquier caso, es innegable que el repertorio poético propuesto en Heroicas expuso como ningún otro conjunto la lectura practicada sobre el tema de España por

2 Tomado de Gomes Ferreira 1990: 152. 
RIVERO MACHINA

los neorrealistas, una lectura de largo recorrido y de permanente presencia. $^{3}$ El testimonio que ofrecerá años después en su autobiografía A Memória das Palavras es, igualmente, una de las exposiciones más claras de cuanto significó la guerra de Espanha para la joven poesía neorrealista en Portugal.

$\mathrm{Na}$ verdade a guerra de Espanha entrou em forma de tempestade pelas casas dos poetas dentro, partiu as vidraças das janelas, varreu a inspiração livresca, e a vida-vida tomou conta das palavras. Alguns poetas pegaram até nas espingardas para haver sangue nos versos. (Gomes Ferreira 1965: 154)

Y si en Heroicas la Guerra Civil de España compone el hilo conductor de todo un poemario, constituyendo el gran monumento neorrealista a la vecina contienda, no resulta difícil encontrar testimonios similares entre otros tantos libros de la escuela del Novo Cancioneiro. Tal es así, que no faltarán textos sobre España y su guerra entre los diez poemarios de la celebérrima colección editorial publicada en Coímbra. En la segunda de sus entregas, los Poemas de Mário Dionísio, se reúne, bajo el título común de $O$ homem sozinho na beira do cais, una serie de poemas escritos entre 1936 y 1938. Entre sus emocionadas piezas, obviamente también conmocionadas por los sucesos de España, un largo poema en cinco partes, titulado "A noite é sem estrelas", reproduce el pesimismo de un pueblo derrotado por el "fantasma quijotesco" al que se soñó vencer.

\author{
Ah! a noite! \\ Minha noite de amor que é sempre imagen. \\ Noite de pesadelos, no leito regelado. \\ Noite de fantasmas quixotescos. \\ Noite como dedos inimagináveis denunciando: derrota! \\ Noite de cão danado, à esquina duma rua de lanterna apagada, \\ encolhido, escondido na parede, apedrejado de longe. \\ Noite de imensa saudade \\ de tudo que se ama e que nunca virá \\ (Mário Dionísio, O homem sozinho na beira do cais, 1938)4
}

\footnotetext{
"José Gomes Ferreira é, talvez, o poeta que mais radicalmente sentiu, pensou e traduziu essa vinculação, relação ou aliança fundamental da Palabra e dos Intelectuais, Palabra que, tal como o espírito humano, não existe desencarnada, mas irrompe nos acontecimentos históricos. No caso concreto do neo-realismo portugués, que tão expresivamente cultivou o sortilégio da palabra, o acontecimento genesíaco foi, como vimos mostrando, a Guerra de Espanha." (Marques Fernandes 2007: 140)

4 Tomado de Pinheiro Torres 1989: 119.
} 
Sanchos contra Quijotes. Un paradigma ibérico contra el Estado Novo y el franquismo

Asistimos pues a la nostalgia por una victoria que se sospecha remota y por la que sin embargo aún se piensa combatir. Con el viejo -y siempre postergado en estos poetas-ideal de sumarse a los milicianos de la República, Dionísio esboza una estampa goyesca de fusilamientos y "no pasarán”.

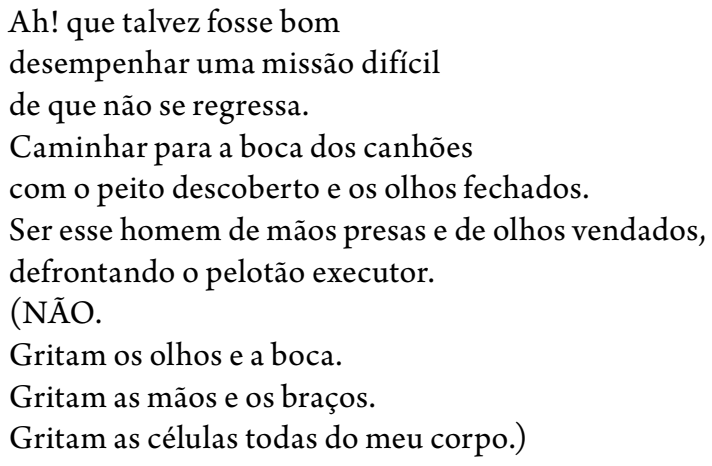

(Mário Dionísio, O homem sozinho na beira do cais, 1938)

En el imaginario neorrealista, por lo tanto, la significación del mito quijotesco atribuye de manera inequívoca un rol marcadamente negativo al Caballero de la Triste Figura, identificado aquí con las vanidades de un idealismo carente de razón tras el que se escudarían las clases privilegiadas -la decadente aristocracia alineada con el bando de los militares golpistas de julio de 1936- frente al insoslayable materialismo histórico de un proletariado encarnado por contraste -como veremos enseguida- por el humilde Sancho Panza.

\section{Los poemas ibéricos de Miguel Torga}

Lejos de la militancia neorrealista y también de sus orígenes en Presença, la trayectoria poética de Miguel Torga y su abundantemente declarada y estudiada "vocación ibérica" no podía pasar por alto el empleo del simbolismo quijotesco. El monumento sobresaliente de esta marcadísima vocación ibérica de Miguel Torga fue, sin lugar a dudas, la colección de Poemas ibéricos que escribiera, en su mayor parte, precisamente durante los años de la guerra de Espanha. Su historia textual y editorial fue, sin embargo, más larga y compleja, inconclusa hasta su publicación definitiva en 1965. Algunos de estos Poemas ibéricos fueron apareciendo parcialmente en diversos lugares y en lo que los resquicios de la censura permitían. Así, en el quinto y último número de su revista Manifesto,

5 Tomado de Pinheiro Torres 1989: 120. 
RIVERO MACHINA

Torga publicaba los siete poemas que componen la sección "História trágicomarítima” sobre la vocación atlántica de Portugal (Manifesto, n 5, julio de 1938, pp. 2-4). Poco después, difundía en la Revista de Portugal -que dirigía Vitorino Nemésio- los poemas "Ibéria”, "A Raça” y "Santa Teresa” (no 5, octubre de 1938, pp. 8-10); así como "Viriato", “O infante” y "D. Sebastião” (no 8, julio de 1939, pp. 463-465). Otros poemas no se adelantarán en revistas, sino en lugares de excepción, como sucede con el poema "Federico Garcia Lorca”, incluido en calidad de homenaje en la Antología poética sobre el granadino preparada por Eugénio de Andrade (Coímbra, Coimbra editora, 1946, pp. 9-10). Excepcional y pionera es, igualmente, la publicación en la emblemática revista leonesa Espadaña de una primera versión al castellano por Pilar Vázquez Cuesta de estos Poemas ibéricos de Torga. Los poemas traducidos por la estudiosa gallega, y presentados bajo el rótulo de "Poemas ibéricos", fueron los mismos, por cierto, que ya se publicaron en Revista de Portugal y Manifesto, a excepción del poema "Mar" (Espadaña, no 43, noviembre-diciembre de 1949). Tras este irregular menudeo, Miguel Torga decide editar en forma de poemario no definitivo parte de este corpus en Alguns Poemas Ibéricos (Coímbra, edición del autor, 1952). Sin embargo, no fue hasta 1965, treinta años después de escribir las primeras versiones de estos poemas, cuando el médico trasmontano editó, definitivamente, sus Poemas ibéricos (Coímbra, edición del autor, 1965). ${ }^{6}$

El libro se compone de varias secciones que articulan una colección de poemas que no se inspiran en España ni en Portugal, sino en la suma de ambas. Acudiendo a la célebre entrada del 11 de noviembre de 1942 del Diário torguiano, encontramos algunas de las claves sobre el "universo ibérico" de su autor.

Explicar ao mundo a natureza da nossa língua, o caminho da nossa história, a terrosidade do nosso chão, a seriedade da nossa paisagem, a intimidade da nossa literatura, a grandeza dos nossos santos, a ferocidade dos nossos hérois, a humanidade dos nossos ladrões e o ingénuo charlatanismo dos nossos políticos, é certamente a maneira mais honrada de conversar no soalheiro universal, e de motivar compreensão dos ouvidos alheios. (Miguel Torga, Diário, II, 11 de noviembre de 1942)

6 Frente a los cuarenta y cinco Poemas ibéricos, en Alguns poemas ibéricos se recogen treinta y cuatro de esas composiciones. En el libro de 1952, solo las secciones "História trágico-telúrica", a falta de un poema, "História trágico-marítima" y "O pesadelo", a falta de dos piezas, aparecen configuradas como tal. Únicamente "História trágico-marítima”, por su parte, no sufre alteraciones en la versión definitiva de Poemas ibéricos. 
Sanchos contra Quijotes. Un paradigma ibérico contra el Estado Novo y el franquismo

No es otro el programa poético acometido en Poemas ibéricos. Las secciones que lo componen nos hablan de una "História trágico-telúrica" y una "História trágico-marítima” - la vocación continental-ibérica y la vocación atlántica de Portugal, respectivamente-, de "Os héroes" -sección central del poemario, a la sazón-y de "O pesadelo" -que como tal se entiende el pasado reciente y el presente histórico de las gentes de Iberia-. Abriendo todas estas secciones a la manera de un pórtico, Miguel Torga coloca el poema "Ibéria", en el que queda definida la Península como universo poemático a desarrollar.

Terra.

Quanto a palavra der, e nada mais.

Só assim a resume

Quem a contempla do mais alto cume,

Carregada de sol e de pinhais.

Terra-tumor-de-angústia de saber

Se o mar é fundo e ao fim deixa passar...

Uma antena da Europa a receber

A voz do longe que lhe quer falar...

Terra de pão e vinho

(A fome e a sede só virão depois,

Quando a espuma salgada for caminho

Onde um caminha desdobrado em dois).

Terra nua e tamanha

Que nela coube o Velho-Mundo e o Novo...

Que nela cabem Portugal e Espanha

E a loucura com asas do seu Povo.

(Miguel Torga, Poemas ibéricos, 1965)

Es así Miguel Torga el poeta que "caminha desdobrado em dois" para cantar el espíritu de un solo pueblo, "do seu Povo"; un pueblo que es a un tiempo "pão e vino" -Sancho-y "loucura com asas" -Quijote-.

La articulación del cuerpo central de Poemas ibéricos se fundamenta, sin embargo, en una serie de veintisiete "Hérois" históricos cuyas semblanzas revelarían la propia naturaleza del ser ibérico: Viriato, Séneca, el Cid, Inés de Castro, Nuno Álvares, el infante don Enrique el Navegante, Torquemada, Vasco da Gama, Hernán Cortés, san Ignacio de Loyola, santa Teresa de Ávila, Camões, Felipe II, san Juan de la Cruz, Cervantes, António Vieira, Goya, Herculano, 
RIVERO MACHINA

Unamuno, Picasso, Pessoa, García Lorca, y alguno más. ${ }^{7}$ A través de esta pléyade de personajes - gobernantes, militares, navegantes, religiosos, escritores, pintores- Miguel Torga procura "una especie de radiografías psicológicas de personajes históricos, escritores o artistas españoles y portugueses a los que considera encarnación de nuestras peculiaridades nacionales" (Vázquez Cuesta 1967: 133). No se trata pues de un catálogo heroico, de "glorias nacionales" como se suele decir-, sino que en todo el recorrido trasciende su espíritu crítico y agridulce, llegando, en el peor de los casos, a tristes representantes del fanatismo y la leyenda negra ibérica como Torquemada, Cortés o Loyola. La historia de Iberia para Torga no es por lo tanto épica, trágica o cómica, sino sencillamente humana. Con todas sus grandezas y sus bajezas.

Conviene tener todo esto presente para acercarnos a la sección final de Poemas ibéricos, titulada "O pesadelo" y compuesta por los poemas "Pesadelo de D. Quixote", "Não passarão" y "Exortação a Sancho". Los poemas están escritos -como los de Gomes Ferreira y Mário Dionísio- en torno al desarrollo de la Guerra Civil española. En Torga, sin embargo, el tratamiento de la figura quijotesca difiere en algunos matices del que hemos observado en A morte de D. Quixote de Gomes Ferreira. Torga coincide con el neorrealista en la necesidad de restituir a Sancho la soberanía de su destino cautivo, pero su visión de don Quijote, por el contrario, no deriva en una rotunda e irrevocable condena moral. En parte porque para Torga -en esa naturaleza dual del pueblo ibérico de que hemos hablado- Quijote y Sancho no son sino el haz y el envés de un mismo espíritu -su admiración por la obra unamuniana al fondo-. Así se desprende del poema que cierra, no por casualidad, Poemas ibéricos: su «Exortação a Sancho» (pp. 76-77).

\author{
Senhor meu, Sancho Pança enlouquecido, \\ Servo vencido \\ Na terra sonhada, \\ Tem a coragem da verdade nua: \\ Olha esta Ibéria que te foi roubada, \\ E que só terá paz quando for tua. \\ Ergue a fronte dobrada \\ E começa a façanha prometida! \\ Cumpre o voto da nova arremetida, \\ Feito aos pés de quem foi \\ O destemido herói \\ Da batalha de ser fiel à vida!
}

\footnotetext{
Dejando al margen la incierta nacionalidad de Viriato, catorce de estos héroes serían españoles -incluyendo a Séneca- y doce portugueses. Para el tratamiento de los españoles véase (Olazagasti-Segovia 1991).
} 
Sanchos contra Quijotes. Un paradigma ibérico contra el Estado Novo y el franquismo

\author{
Nega-te a ser passiva testemunha \\ Do amor cobiçoso \\ Que os falsos namorados \\ Fazem crer impoluto e arrebatado \\ Àquela que reflecte o céu lavado \\ Nos olhos confiados. \\ Venha o teu grito de transfigurado: \\ Ai, no se muera!... E a donzela acorda \\ E renega o idílio traiçoeiro. \\ Venha o Sancho da lança e do arado, \\ E a Dulcineia terá, vivo a seu lado, \\ O senhor D. Quixote verdadeiro!
}

(Miguel Torga, Poemas ibéricos, 1965)

La Iberia torguiana es, en suma, el compendio de héroes y antihéroes reconocidos por la historia o sumidos en el anonimato del pueblo llano. Una sola nación de quijotes -desde Viriato a Unamuno-y pastores -desde Viriato a Sancho Panza- ligados inevitablemente a su agridulce y humanísimo destino ibérico. En su doble componente de locura y realidad.

\title{
Sancho contra Quijote en Gabriel Celaya y José Saramago
}

Hemos visto hasta aquí, por lo tanto, tres lecturas muy semejantes en las que la figura de Sancho aparece dignificada o directamente rebelada contra un don Quijote que no es sinónimo de lucidez o idealismo, sino de la vanidad de lo que no es cierto, de lo que no se come ni germina en el campo. Tres lecturas muy apegadas al contexto de la Guerra Civil española y escritas por aquellas fechas, a pesar de que no fueran editadas hasta 1941 en el caso de Dionísio, hasta 1948 en el de Gomes Ferreira o hasta 1952-1965 en el de Torga. Hemos comprobado, en suma, un tratamiento semejante, a pesar de que los dos poetas neorrealistas lo hicieran desde la militancia comunista y Torga desde la libertad individual de un creador comprometido con su tiempo. Libertad que le permite acercarse a don Quijote con cierta comprensión o benevolencia, si se quiere. Siempre en pos de un símbolo literario que entender -Torga era un declarado admirador de Cervantes- más que de un objeto político al que derrocar.

Sobre esta construcción de un Sancho levantado en su dignidad contra la locura de Don Quijote encontraremos ecos en escritores tan emblemáticos como José Saramago o el poeta español Gabriel Celaya. Un Sancho que 
RIVERO MACHINA

terminaba así por encarnar la dignidad de los pueblos portugués y español pese a encontrarse por aquellos años bajo el yugo falaz y grandilocuente de dos dictaduras como la salazarista y la franquista. Verdadero icono de resistencia, Sancho Panza mutaba así en emblema de cordura y dignidad a uno y otro lado de la Raya. Podría decirse que Celaya y Saramago consuman, más de dos décadas después, aquel afán ibérico adelantado por Miguel Torga.

No en vano, el poema "A Sancho Panza" de Gabriel Celaya se publicó en 1955 en uno de sus poemarios centrales, un libro titulado Cantos iberos. Rótulo este último, por cierto, cuya similitud con el título de los Poemas ibéricos torguianos es cuanto menos sugerente, sobre todo si tenemos en cuenta que tres años antes, en 1952, aparecía la versión provisional de Alguns poemas ibéricos. En el poema de Celaya, efectivamente, volvemos a encontrarnos con un Sancho Panza que encarna la grandeza de los pequeños, de los derrotados, del pueblo.

Sancho-bueno, Sancho-arcilla, Sancho-pueblo,

tu lealtad se supone,

tu aguante parece fácil,

tu valor tan obligado como en la Mancha lo eterno.

Sancho-vulgar, Sancho-hermano,

Sancho, raigón de mi patria que aún con dolores perduras, y, entre cínico y sagrado, pones tu pecho a los hechos, buena cara a malos tiempos.

Sancho que damos por nada, mas presupones milenios de humildad bien aceptada, no eres historia, te tengo como se tiene la tierra, patria y matria, macerada.

Sancho-vulgo, Sancho-nadie, Sancho-santo, Sancho de pan y cebolla trabajado por los siglos de los siglos, cotidiano, vivo y muerto, soterrado.

Se sabe sin apreciarlo que eres quien es, siempre el mismo, Sancho-pueblo, Sancho-ibero, Sancho entero y verdadero, Sancho de España es más ancha que sus mil años y un cuento

(Gabriel Celaya, Cantos iberos, 1955) 
Sanchos contra Quijotes. Un paradigma ibérico contra el Estado Novo y el franquismo

La capacidad moral del personaje cervantino de Sancho Panza para encarnar la historia milenaria de la Hispania romana, de la Iberia telúrica, alejada sin embargo de toda épica grandilocuente y vinculada a la materialidad del "pan" y la "cebolla" es, en este sentido, muy semejante a la propuesta torguiana. Igualmente, la identificación de la figura complementaria de Don Quijote con las clases privilegiadas a las que otrora -años treinta- se soñó con derrocar, la adscripción del Caballero de la Triste Figura con la categoría social del "señorito", conecta los siguientes versos de Celaya con el enfoque practicado por el neorrealismo militante de Gomes Ferreira y Dionísio.

Hoy como ayer, con alarde,

los señoritos Quijano siguen viviendo del cuento, y tú, Sancho, les toleras y hasta les sigues el sueño por instinto, por respeto, porque creer siempre es bueno.

Cabalgando en tus espaldas se las dan de caballeros y tú, pueblo, les aguantas, y levantas -tentetiesolo que puede levantarse. $Y$ aun sabiendo lo que sabes nunca niegas tus servicios: ¡santo y bueno!

Sancho-Quijote y a un tiempo Sancho de basta de cuentos, Sancho-amén de tiempo al tiempo, Sancho que aun hecho y derecho, ya de vuelta del Imperio, al señorito Quijano le tratas de caballero.

(Gabriel Celaya, Cantos iberos, 1955)

En Celaya se suma, pues, el Sancho histórico torguiano y el Sancho revolucionario de los neorrealistas. Celaya cifra en Sancho Panza, en suma, todo el simbolismo de la resistencia antifranquista $-y$, por simpatía, antisalazarista- al tiempo que desarrolla, en su materialidad, la estética de la "poesía social" entonces hegemónica en España. Todo un alegato, al cabo, contra la autonomía artística del lenguaje poético, contra la "poesía pura", en definitiva; o, en las aquí citadas palabras de Gomes Ferreira, contra "o álcool da arte-pura-para-esquecer".

Hombre a secas, Sancho-patria, pueblo-pueblo, pura verdad, fiel contraste

de los locos que te explotan para vivir del recuerdo, ¡ya ha llegado tu momento! 


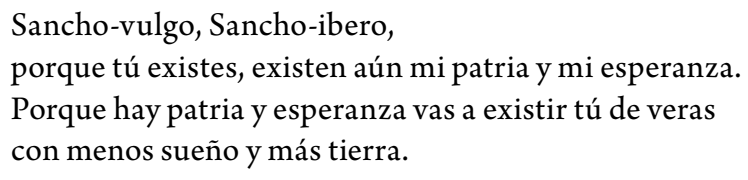

Tu libertad es instinto. Tus verdades son sencillas: al pan, pan, y al vino, vino, y a cada cual lo debido:

lo que le cumple por hombre con un único camino.

Sancho-firme, Sancho-obrero, ajustador, carpintero, labrador, electricista, Sancho sin nombre y con manos de constructor, y un oficio, viejo y nuevo, vida al día.

Quiero darte la confianza que pretendieron robarte. Quiero decirte quién eres.

Quiero mostrarte a ti mismo tal como tú fuiste siempre, Sancho-humilde, Sancho-fuerte.

En ti pongo mi esperanza porque no fueron los hombres que se nombran los que hicieron más acá de toda Historia -polvo y paja- nuestra patria, sino tú como si nada.

Sancho-tierra, Sancho-santo, Sancho-pueblo, tomo tu pulso constante, miro tus ojos que brillan aún después de los desastres. Tú eres quien es. ¡Adelante!

(Gabriel Celaya, Cantos iberos, 1955)

En la estela del "Sancho-pueblo" de Celaya levantado contra "los señoritos Quijano”, y en la del Sancho de sus compatriotas Torga, Dionísio y Gomes Ferreira, el futuro premio Nobel José Saramago también se acercará a las figuras de Dulcinea, Don Quijote y Sancho Panza en tres poemas sucesivos. Tales poemas aparecieron en su primer volumen de poesía, Os poemas possíveis (Lisboa, Portugália) de 1966. También en Saramago, de los tres personajes cervantinos -la difusa Dulcinea, el envanecido Quijote y el leal Sancho- solo el escudero-labriego aparece en toda su grandeza. Por ello, la actitud del sujeto lírico planteado por Saramago marca escépticas distancias frente a las fantasías de Don Quijote, el cual cae así en su definitivo descrédito. Aquel descrédito proclamado treinta años atrás por Gomes Ferreira. 
Sanchos contra Quijotes. Un paradigma ibérico contra el Estado Novo y el franquismo

\author{
Não vejo Dulcineias, D. Quixote, \\ Nem gigantes, nem ilhas, nada existe \\ Do teu sonho de louco. \\ Só moinhos, mulheres e Baratárias, \\ Coisas reais que Sancho bem conhece \\ E para ti são pouco
}

(José Saramago, Os poemas possíveis, 1966)

En contraposición, con Saramago se consuma, efectivamente, la consagración de la superioridad moral del humilde Sancho Panza sobre la decadente hidalguía de Don Quijote. Se completa, en definitiva, la subversión de la pareja cervantina, la rebelión de los "sanchos" contra los "quijotes". También en Saramago, como en el resto de los textos observados, es en la honesta materialidad del labrador, frente al idealismo del enloquecido aristócrata, donde radica toda su grandeza moral.

\author{
Capaz de medos, sim, mas não de assombros. \\ Para assombros outra alma se precisa \\ Mais nua e desarmada. \\ Mas dessa bruta mão cai a semente \\ Que a teu amo sustenta, e sem o pão, \\ Até assombro é nada
}

(José Saramago, Os poemas possíveis, 1966)

Observados, pues, los textos poéticos de José Gomes Ferreira, Mário Dionísio, Miguel Torga, Gabriel Celaya y José Saramago, resulta inevitable constatar la existencia de un corpus coherente y definido dentro de la poesía española y portuguesa $-\mathrm{y}$ particularmente en esta última- durante las décadas centrales del siglo XX. Un corpus delimitado en el que el mito quijotesco es trasmutado en símbolo de una lucha de clases en la que el materialismo de Sancho derroca, al menos moralmente, el vano idealismo de su señor. La construcción de esta lectura se encuentra, asimismo, directamente ligada al periodo de la Guerra Civil española y a la simpatía profesada por los poetas antisalazaristas -Gomes Ferreira, Dionísio, Torga- hacia la Segunda República española. Su vigencia, sin embargo, se extenderá -como las consecuencia de dicha guerra- durante las siguientes tres décadas, conformando parte del imaginario poético de la oposición comunista y democrática a los regímenes militares de Francisco Franco y António de Oliveira Salazar, encontrando así ecos directos en poemarios posteriores como los Cantos iberos de Gabriel Celaya, en 1955, y Os poemas possiveis de José Saramago, en 1966. 
RIVERO MACHINA

\author{
Antonio Rivero Machina \\ antoniorm@unex.es \\ Facultad de Filosofía y Letras de Cáceres \\ Avda. de la Universidad s/n \\ 10003 Cáceres \\ ESPAÑA / SPAIN
}

\title{
Obras citadas
}

Abreu, Ma F. de. 2006. O Quixote na Voz dos Escritores Portugueses. - M. A. da Costa Vieira, ed., Dom Quixote: A Letra e os Caminhos. São Paulo: Universidade de São Paulo, 297-316.

Celaya, G. 1955. Cantos iberos. Alicante: Verbo.

Gomes Ferreira, J. 1965. A Memória das palavras. Ou o gosto de falar de mim. Lisboa: Portugália Editora.

Gomes Ferreira, J. 1990. Poeta Militante I. Lisboa: Publicações D. Quixote.

Marques Fernandes, J. 2007. Recepção da Guerra de Espanha pelos intelectuais portugueses. Contexto e divergencia - Diacrítica. Série filosofía/cultura. Revista do Centro de Estudos Humanísticos, 21-2, 117-160.

Olazagasti-Segovia, E. 1991. Los héroes españoles de Miguel Torga - Hispania, 74-2, 290-297.

Pinheiro Torres, A., ed. 1989. Novo Cancioneiro, Lisboa: Caminho.

Saramago, J. 1966. Os poemas possíveis. Lisboa: Portugália Editora.

Torga, M. 1949. Diário II. Coimbra: Ed. del autor.

Torga, M. 1965. Poemas ibéricos. Coimbra: Ed. del autor.

Vázquez Cuesta, P. 1967. Miguel Torga. Noticia y selección - Revista de Occidente, 2a ép., 53, 129-136. 